\title{
Massive upper gastrointestinal bleeding post-Whipple's surgery from anastomotic varices due to mesenteric hypertension
}

A 45-year-old man was admitted with hematemesis. He had undergone Whipple's surgery 7 years previously for a $5-\mathrm{cm}$ serous cystadenoma of the pancreatic head. Upon presentation, he was hypotensive (blood pressure $82 / 59 \mathrm{mmHg}$ ) and tachycardic (110 beats/min), with a hemoglobin of $6.8 \mathrm{~g} / \mathrm{dL}$. Gastroscopy revealed bleeding anastomotic varices alongside the gastrojejunal anastomosis ( Fig. 1). Hemostasis was secured with a Boston Resolution clip ( $\vee$ Video 1). Computed tomography (CT) scanning, followed by mesenteric angiography in the portal venous phase and $\mathrm{CT}$ arterioportography showed proximal superior mesenteric vein (SMV) occlusion, with a large collateral vein draining the small bowel into the anastomotic varices, which decompressed via the enlarged left coronary vein (LCV) into a patent portal vein ( $\triangleright$ Fig. 2 ). The occluded SMV was recanalized, dilated to $8 \mathrm{~mm}$, and stented with a $7 \times 29-\mathrm{mm}$ Omnilink stent via a transhepatic approach, thereby reestablishing antegrade flow with subsequent collapse of the collateral vein and anastomotic varices ( $>$ Fig. $\mathbf{3}$ ).

Gastrointestinal bleeding is a complication reported in $2 \%-8 \%$ of patients following a Whipple procedure [1]. Sources of upper gastrointestinal bleeding include pseudoaneurysms, pancreatic fis-

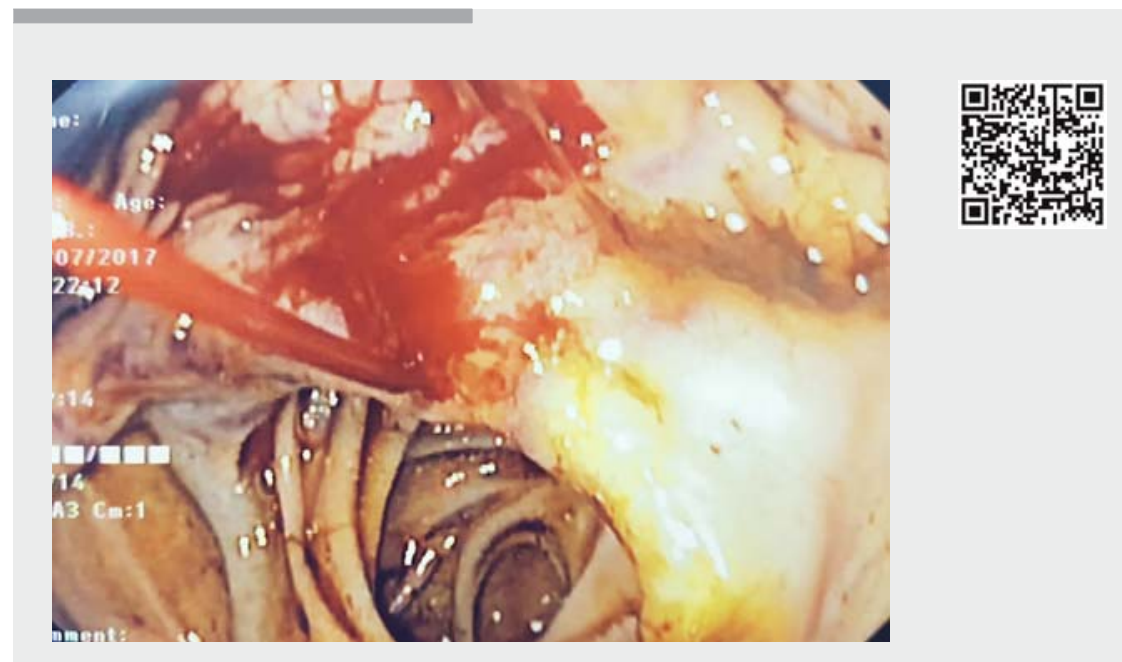

Video 1 A bleeding anastomotic varix is seen alongside the gastrojejunal anastomosis and is secured with a Boston resolution clip.

tulas, anastomotic ulcers, and ectopic varices [2 -5]. We report a case of bleeding anastomotic varices that developed from mesenteric hypertension as a result of SMV occlusion following surgery. As the small bowel was solely draining back to the portal vein via a collateral vein and anastomotic varices, endoscopic glue injection into the anastomotic varices could have led to bowel ischemia. Successful stenting of the occluded SMV resulted in the re-establishment of normal hemodynamics, decompressing the anastomotic varices, and therefore preventing future bleeding episodes.

Endoscopy_UCTN_Code_TTT_1AO_2AD

\section{Competing interests}

None 

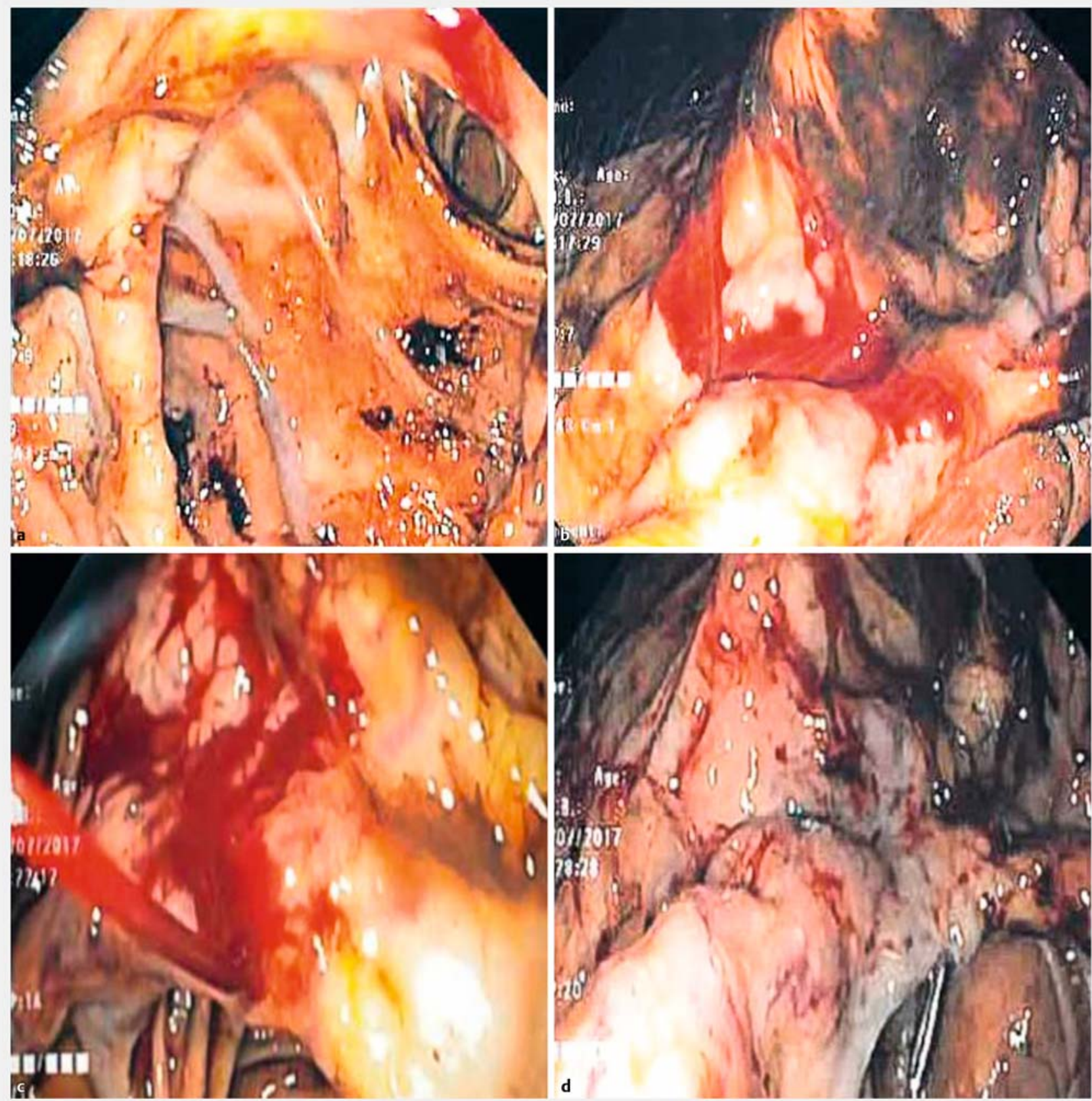

- Fig. 1 Endoscopic images showing bleeding anastomotic varices alongside the anastomosis of the gastroduodenostomy. Endoscopic hemostasis of the bleeding varices was achieved using a Boston Resolution clip. 


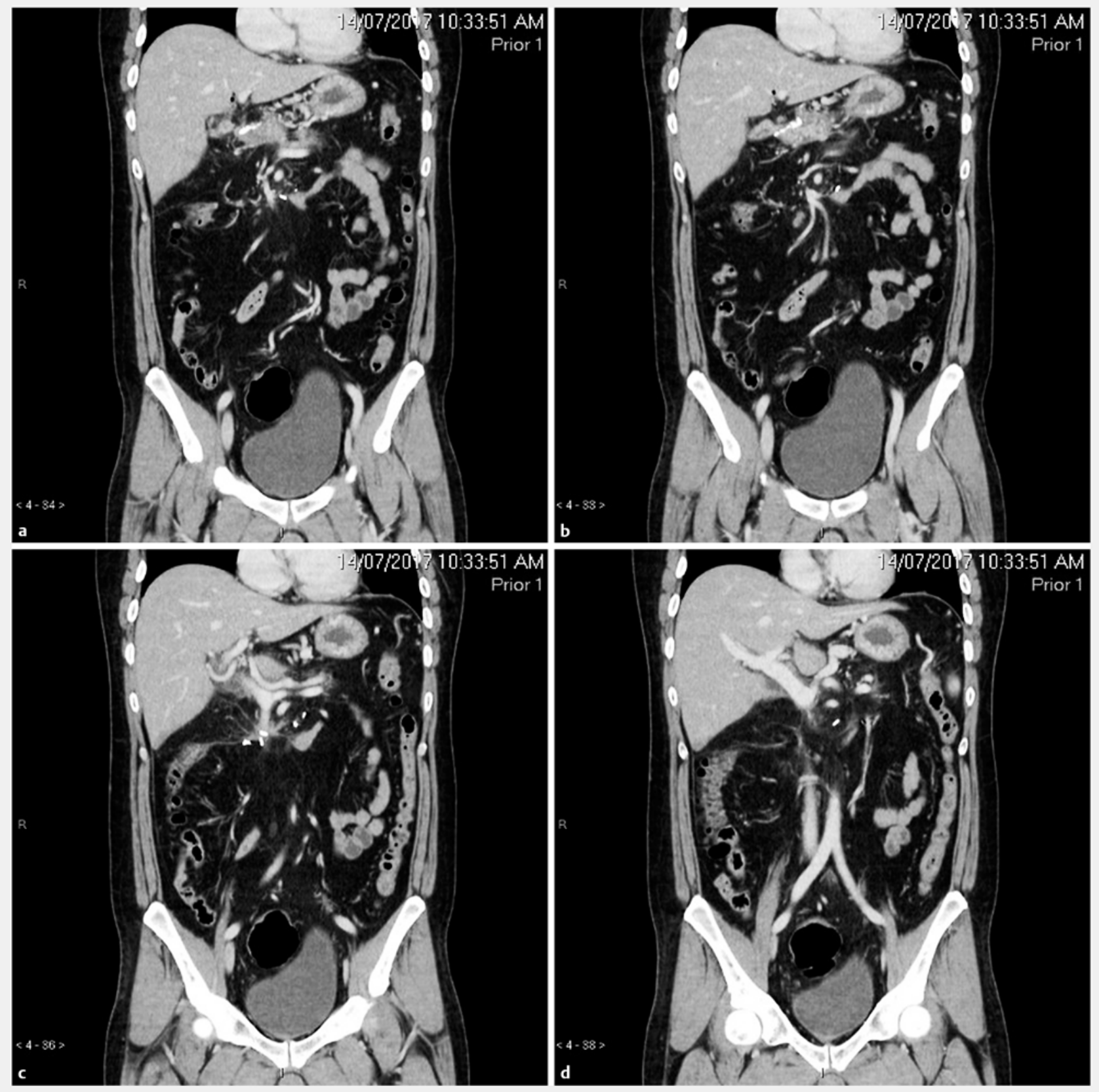

Fig. 2 Computed tomography scan images of the abdomen showing: $\mathbf{a}$ the anastomotic varices; $\mathbf{b}$ a collateral vein with occluded superior mesenteric vein (SMV); c occluded SMV; d occluded portal vein and left coronary vein. 

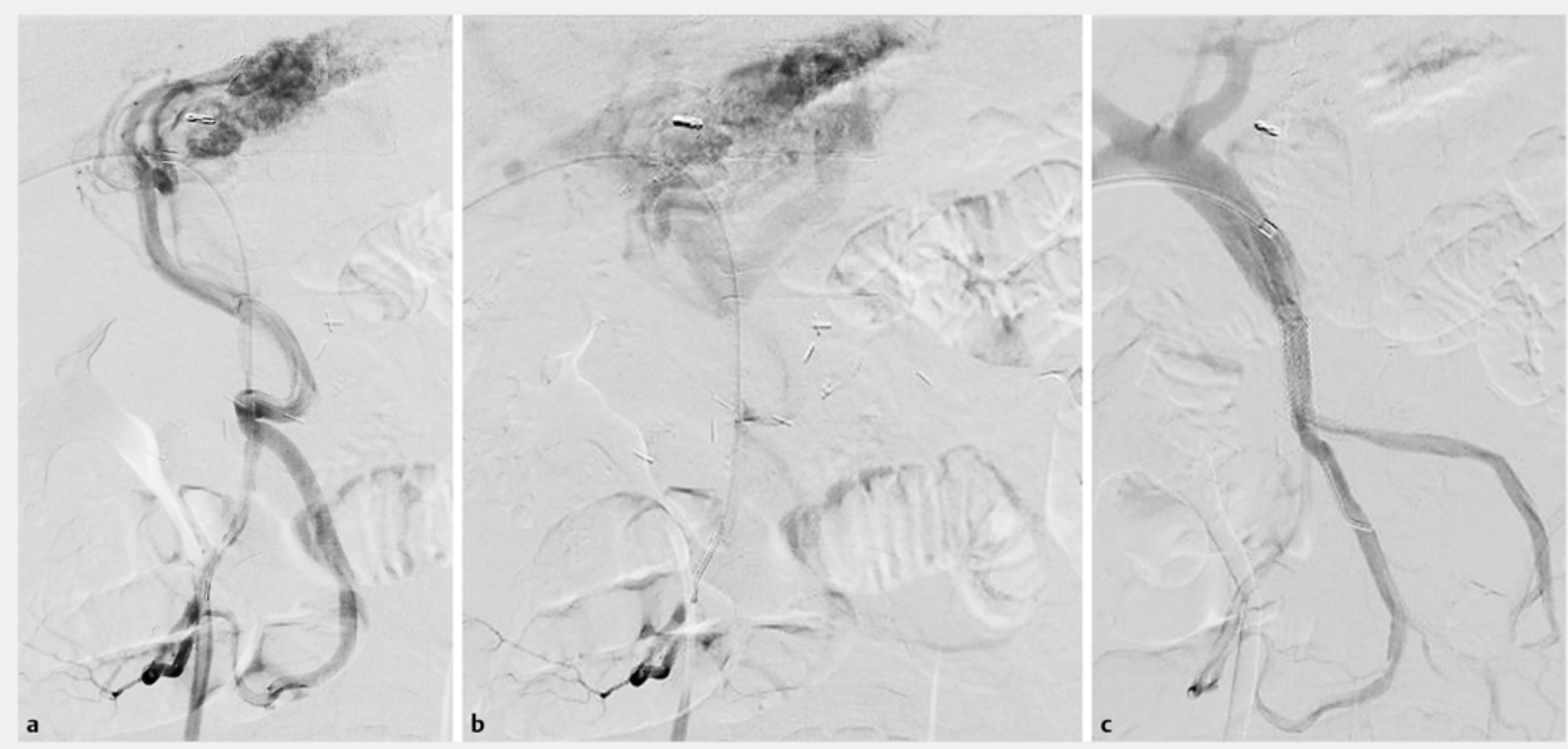

- Fig. 3 Computed tomography of arterioportography showing: a the collateral vein draining into anastomotic varices; $\mathbf{b}$ the vaices draining into the left coronary vein; $\mathbf{c}$ the occluded superior mesenteric vein recanalized, dilated, and stented with a $7 \times 29-\mathrm{mm}$ Omnilink stent.

The authors

\section{Yu Jun Wong', Farah Gillian Irani², Malcolm} Tan $^{1}$, Melissa Teo ${ }^{3,4}$

1 Department of Gastroenterology and Hepatology, Changi General Hospital, Singapore

2 Department of Vascular and Interventional Radiology, Singapore General Hospital, Singapore

3 Division of Surgical Oncology, Singapore General Hospital, Singapore

4 National Cancer Center, Singapore

\section{Corresponding author}

\section{Yu Jun Wong, MD}

Department of Gastroenterology and Hepatology, Changi General Hospital, 2 Simei Street 3, 529889, Singapore

Eugene.wong@mohh.com.sg

\section{References}

[1] Ellison EC. Evidence-based management of hemorrhage after pancreaticoduodenectomy. Am J Surg 2007; 194: 10 - 12

[2] Ali S, Asad UR, Udayakumar N. An Unusual Cause of recurrent gastrointestinal bleeding after Whipple's surgery. Gastroenterology 2017; 153: e1-e2

[3] Damle A, Clemenzi AA, Jabbour $\mathrm{N}$ et al. Rare cause of delayed upper gastrointestinal bleeding after pancreaticoduodenectomy. Pancreas 2012; 13: 222-225

[4] Schäfer M, Heinrich S, Pfammatter T et al. Management of delayed major visceral arterial bleeding after pancreatic surgery. HPB (Oxford) 2011; 13: $132-138$

[5] Gomes AP, Guede PE, Rosa L et al. Splancnic hypertension following a Whipple procedure: interdisciplinary approach. EURORAD: Radiological Case Database. Available from: http://www.eurorad.org/eurorad/case.php? id=10218. Accessed: 9 February 2018

\section{Bibliography}

DOI https://doi.org/10.1055/a-0595-7507

Published online: 9.5.2018

Endoscopy 2018; 50: E159-E162

(c) Georg Thieme Verlag KG

Stuttgart · New York

ISSN 0013-726X

\section{ENDOSCOPY E-VIDEOS}

https://eref.thieme.de/e-videos

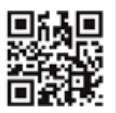

Endoscopy E-Videos is a free access online section, reporting on interesting cases and new

techniques in gastroenterological endoscopy. All papers include a high quality video and all contributions are freely accessible online.

This section has its own submission website at https://mc.manuscriptcentral.com/e-videos 